\title{
Addressing Prediabetes in Childhood Obesity Treatment Programs: Support from Research and Current Practice
}

\author{
Matthew A. Haemer, MD, MPH, H. Mollie Grow, MD, MPH, ${ }^{2}$ Cristina Fernandez, MD, ${ }^{3}$ \\ Gloria J. Lukasiewicz, MS, RN, ${ }^{4}$ Erinn T. Rhodes, MD, MPH, Laura A. Shaffer, PhD, ${ }^{6}$ \\ Brooke Sweeney, MD, Susan J. Woolford, MD, MPH, and Elizabeth Estrada, MD ${ }^{9}$
}

\section{Abstract}

Background: Type 2 diabetes mellitus (T2DM) and prediabetes have increased in prevalence among overweight and obese children, with significant implications for long-term health. There is little published evidence on the best approaches to care of prediabetes among overweight youth or the current practices used across pediatric weight management programs.

Methods: This article reviews the literature and summarizes current practices for screening, diagnosis, and treatment of prediabetes at childhood obesity treatment centers. Findings regarding current practice were based on responses to an online survey from 28 pediatric weight management programs at 25 children's hospitals in 2012. Based on the literature reviewed, and empiric data, consensus support statements on prediabetes care and T2DM prevention were developed among representatives of these 25 children's hospitals' obesity clinics.

Results: The evidence reviewed demonstrates that current T2DM and prediabetes diagnostic parameters are derived from adultbased studies with little understanding of clinical outcomes among youth. Very limited evidence exists on preventing progression of prediabetes. Some evidence suggests that a significant proportion of obese youth with prediabetes will revert to normoglycemia without pharmacological management. Evidence supports lifestyle modification for children with prediabetes, but further study of specific lifestyle changes and pharmacological treatments is needed.

Conclusion: Evidence to guide management of prediabetes in children is limited. Current practice patterns of pediatric weight management programs show areas of variability in practice, reflecting the limited evidence base. More research is needed to guide clinical care for overweight youth with prediabetes.

\section{Introduction}

$\mathbf{T}$ he increased prevalence of obesity, particularly severe obesity, in all pediatric age groups, has been accompanied by an increase in type 2 diabetes mellitus (T2DM), prediabetes, and insulin resistance (IR). ${ }^{1-4}$ Along with other comorbidities of obesity, including hypertension, dyslipidemia, fatty liver disease, musculoskeletal disorders, and cardiovascular disease, T2DM and its complications represent a significant cause of long-term disability within the US population and a challenge to the resources of the US healthcare system..$^{5-7}$ Still, little evidence exists in pediatric populations for effective prevention and treatment of T2DM.,6,8 Currently, it is estimated that one third of US youth are overweight or obese, and up to $15 \%$ of adolescents may have prediabetes and/or diabetes. ${ }^{1}$

\footnotetext{
'Department of Pediatrics, Section of Nutrition, University of Colorado School of Medicine, Aurora, CO.

${ }^{2}$ Department of Pediatrics, University of Washington School of Medicine, Seattle, WA.

${ }^{3}$ Department of Pediatrics, Creighton University School of Medicine, Omaha, NE.

${ }^{4}$ Children's Hospital Association, Alexandria, VA.

${ }^{5}$ Division of Endocrinology, Boston Children's Hospital, Boston, MA.

${ }^{6}$ Department of Psychiatry and Behavioral Sciences, University of Louisville School of Medicine, Louisville, KY.

${ }^{7}$ Department of Pediatrics, University of Louisville School of Medicine, Louisville, KY.

${ }^{8}$ Department of Pediatrics, University of Michigan, Ann Arbor, MI.

${ }^{9}$ Division of Endocrinology, Connecticut Children's Medical Center, Hartford, CT.
} 
Adolescents and young adults with T2DM are expected to lose 15 years from their life expectancy and may experience severe, chronic complications by their forties. ${ }^{7,9-11}$ Most diagnostic tools and therapeutic interventions currently in use for pediatric T2DM are based on information extrapolated from adult literature. However, the pathophysiology and response to treatment varies between children and adults. The TODAY study, the first long-term study of children with T2DM, and others have reported faster progression of T2DM and beta-cell failure in children, compared to adults, and poor treatment results. ${ }^{12-15}$

Data collected from 2001 through 2005 as part of the SEARCH study, ${ }^{16}$ a large, multi-center study of physiciandiagnosed diabetes among youth 0-19 years of age, provide estimates of prevalence and incidence rates of T2DM by age and ethnicity. The prevalence of T2DM in 2001 was lowest among non-Hispanic white youths $10-19$ years of age at 0.18 in 1000 , with an incidence of 3.7 per 100,000 person-years during the 4-year study. ${ }^{17}$ Prevalence and incidence rates were higher among African American (1.06 in 1000; 19.0 per 100,000 person-years), Hispanic $(0.46,11.6)$, and Asian/Pacific Island youth $(0.52,12.1)$ than non-Hispanic white youth, with the highest rates among Navajo youth $(1.45 ; 27.7) .{ }^{18-21}$

The impetus to complete this survey of current practice and review of current evidence stems from the high prevalence of childhood and adolescent obesity, increasing diagnosis of prediabetes and T2DM, and interest in earlier identification and prevention. ${ }^{22,23}$ The primary aims of the article are to identify practices supported by evidence and report consensus of current practice among childhood obesity specialists for two areas: (1) screening of obese children and adolescents for prediabetes and T2DM and (2) prevention of progression from prediabetes to T2DM. This article describes the practices of medical weight management clinics, but is also relevant to primary care providers who either manage obese children collaboratively with weight management programs or those who must address these issues without access to outpatient tertiary care weight management. ${ }^{2,24}$ The article also highlights subsets of the pediatric population identified as having unique needs or differences with respect to the diagnosis and management of prediabetes, such as specific age groups, ${ }^{25}$ racial/ethnic groups, ${ }^{2,9,10}$ and patients with cooccurring conditions or treatments (e.g., antipsychotics).

\section{Methods}

The clinical practices that are included in this literature review and survey were identified by consensus of the Medical Management Committee of the FOCUS on a Fitter Future (FFF) Group, sponsored by the Children's Hospital Association (CHA). Over 5 years (2008-2013), the FFF group of over 100 representatives from 28 weight management programs at children's hospitals across the United States met in person quarterly and by telephone weekly to monthly. ${ }^{26}$ Each institution self-selected to participate in FFF by an application process available to 250 member institutions of the CHA. The FFF group was unique during this time period as a multidisciplinary longitudinal working group of clinical experts and researchers focusing on the treatment of childhood obesity, particularly severe obesity.

Components of practice were included in this survey and review because the committee judged each to raise relevant clinical questions, have uncertain evidence support, and/or be potential sources of variation in care. Current practices are reported from a survey of 28 pediatric weight management programs at 25 children's hospitals with wide geographic distribution across the United States. The survey was completed by at least one provider from each of the sites participating in the FFF group in 2012. Three hospitals had more than one obesity clinic or program employing different clinical approaches and therefore completed a survey for each program to capture practice variation.

The interprofessional Medical Management Committee from FFF (the Committee) rated the quality of available evidence and determined the strength of support for each practice using a framework described by the American Academy of Pediatrics (AAP) Steering Committee on Quality Improvement and Management. ${ }^{27}$ The quality of evidence supporting each practice was assigned as: A. Welldesigned randomized, controlled trials (RCTs) or diagnostic studies on relevant populations, B. RCTs with minor limitations or overwhelmingly consistent observational studies, C. Observational studies, or D. Expert opinion. The quality of evidence and the balance of benefits and harms for each practice were weighed to arrive at a consensus statement within the following categories: strong support for the practice; support for the practice; an option to consider the practice; no position; or a do not support statement for the practice. Conclusions of the Committee were presented at a meeting of the entire FFF group, from which feedback was incorporated. The revised statements were approved by the entire FFF group as consensus statements. Members of the following disciplines were involved in the review process: pediatricians, pediatric endocrinologists, dietitians, psychologists, social workers, exercise physiologists, and physical therapists. The group identified opportunities for further research based on evidence reviewed and variations within current practice.

\section{Results}

\section{Identification of Risk}

The American Diabetes Association (ADA) Expert Committee on the Diagnosis and Classification of Diabetes Mellitus first recognized prediabetes in $1997 .{ }^{28}$ Prediabetes can be defined by abnormal glucose regulation, including impaired fasting glucose and/or impaired glucose tolerance (IGT) and/or glycosylated hemoglobin (A1c). Data from adult and adolescent studies have shown that prediabetes, particularly in those with an elevated BMI, significantly increases the risk of developing diabetes, but is reversible. ${ }^{29}$ In one study, up to $50 \%$ of severely obese adolescents with prediabetes returned to normal glucose tolerance over 
20 months, whereas $24 \%$ showed progression from prediabetes to diabetes, ${ }^{29}$ and those with the highest BMI had the highest risk of disease progression. Another study showed that $75 \%$ of obese white teens with IGT returned to normal glucose metabolism, whereas $2 \%$ progressed to diabetes. ${ }^{30}$ Based largely on data from the Diabetes Prevention Program (DPP) Research Group study showing successful delay or prevention of onset of T2DM in adults, ${ }^{31}$ there is mounting interest in early detection of prediabetes in childhood.

Clinical screening. Medical providers who routinely carry out laboratory screening of obese children, as recommended by professional societies, are likely to identify some children with blood glucose or A1c measurements in the prediabetes range. Table 1 summarizes recommendations for T2DM screening adapted from the 2007 Expert Committee Re-

Table I. Type 2 Diabetes Screening in Asymptomatic Pediatric Patients ${ }^{\mathrm{a}, 32}$

BMI criteria for screening

I. All children or adolescents who are severely obese (BMI $>99$ th percentile)

2. Children or adolescents at the earlier age of 10 or onset of puberty with

a) Obesity (BMI $\geq 95$ th percentile)

b) Overweight (BMI 85th-<95th percentile) with one or more additional risk factors

Risk factors

- Family history of T2DM in first- or second-degree relative

- High-risk race/ethnicity (African American, Latino, Native American, Asian American, or Pacific Islander)

- Signs of insulin resistance or conditions associated with insulin resistance (hypertension [systolic or diastolic blood pressure $>95$ th percentile for age and sex], dyslipidemia, polycystic ovary syndrome, acanthosis nigricans, or small for gestational age at birth)

- Maternal history of diabetes or gestational diabetes during the child's gestation, low or high birth weight

- Patients prescribed SGAPs

Age at initial testing

- 10 years or at onset of puberty if puberty occurs at a younger age.

- Under age 10, or prepubertal if child has BMI >99th percentile or has one or more additional risk factors.

Retesting

- Biannually if normal, more frequently for abnormal values, rapid increases in weight, development of other comorbidities (hypertension or dyslipidemia), and/or onset of puberty.

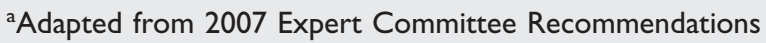
Regarding the Prevention, Assessment, and Treatment of Child and Adolescent Overweight and Obesity. ${ }^{32}$

SGAPs, second-generation antipsychotics. commendations Regarding the Prevention, Assessment, and Treatment of Child and Adolescent Overweight and Obesity. ${ }^{32}$

Special at-risk populations. In addition to obesity, multiple factors add to diabetes risk and warrant consideration. ${ }^{33,34}$ Genetic and environmental risk factors include female gender, sedentary behavior, and family history of T2DM. ${ }^{35}$ Female adolescents are 1.7 times more likely than boys to develop T2DM. ${ }^{36,37}$ At least $74 \%$ of children with T2DM have a first- or second-degree relative with the disorder. ${ }^{38}$ Risk is increased if a parent develops T2DM before age $30 .{ }^{39}$ Prenatal nutrition and intrauterine environment affect risk; low and high birth weight and maternal gestational diabetes or T2DM are the greatest risk factors. ${ }^{39-44}$ Ethnic minorities are at higher risk, including African Americans, Hispanics, and Native Americans. ${ }^{2,10}$ Finally, fat distribution plays a role; children who have central obesity with higher visceral or abdominal fat stores are at higher risk for IR and progression to diabetes. ${ }^{45,46}$

Patients prescribed second-generation antipsychotics (SGAPs) are another group at increased risk for weight gain and secondary diabetes. Among adults with schizophrenia and affective disorders taking SGAPs, the prevalence of diabetes is estimated at 1.5-2.0 times that of the general population. ${ }^{47}$ The pediatric literature is limited; however, one retrospective chart review estimated a 4-fold increased incidence of diabetes among SGAP-exposed pediatric patients, compared to nonpsychotropic medication users. ${ }^{48}$ An observational study of metabolic effects of SGAP therapy in children found an average weight gain of $8.5 \mathrm{~kg}$ in 11 weeks. ${ }^{49}$

Clinical practice by children's hospital-based weight management clinics in screening for prediabetes and type 2 diabetes mellitus. All respondents, representing 28 programs at 25 children's hospitals, indicated that they screen patients for prediabetes and T2DM. Twenty five clinics reported the criteria used to target screening. The majority $(n=18$ of $25 ; 72 \%)$ used BMI as a criterion; however, cutpoints varied among programs (four screen for BMI $\geq 95$ th percentile, three for $\geq 85$ th percentile, one for $>40$ $\mathrm{kg} / \mathrm{m}^{2}$, and one for $\geq 99$ th percentile or $\geq 95$ th percentile with comorbidities). Seven sites screen all referred patients. Additional factors used to target screening included acanthosis nigricans $(n=4)$, family history of T2DM $(n=2)$, age $(n=3)$, and clinical signs of diabetes $(n=1)$.

Consensus statement of Focus on a Fitter Future on clinical screening. Overweight children with cardiometabolic comorbidity and obese children should be screened periodically for prediabetes and T2DM after age 10 years or after onset of puberty (Evidence D). Early identification of prediabetic or diabetic state may prevent progression of disease or facilitate disease management. Additional study of the predictive value of abnormal blood glucose measures for the development of T2DM in children is needed. 


\section{Laboratory Screening and Diagnostic Tests}

Tests recommended by the ADA for screening and diagnosing prediabetes and diabetes include fasting plasma glucose (FPG), A1c, and a 2-hour oral glucose tolerance test (OGTT). ${ }^{38,50}$ Test selection for individual patients may vary based on the clinical findings, risk factors, and resources available. Relative advantages of fasting glucose and $\mathrm{A} 1 \mathrm{c}$ as screening tests are listed in Table $2,{ }^{50}$ and diagnostic cutoffs are listed in Table $3 .{ }^{38,50}$ An analysis of laboratory data from 1156 overweight and obese adolescents from National Health and Nutrition Examination Survey 1999-2006 found that an A1c cutoff of 6.5\% was $75 \%$ sensitive for identifying diabetes, compared to a single FPG, though this study was limited by a very low number of undiagnosed diabetics $(n=4)$ and the possibility of erroneous reports of fasting. ${ }^{51}$ The same study found that, for adolescents compared to adults, A1c was a significantly worse predictor of prediabetes defined by FPG (area under the receiver operating curve, 0.61 vs. 0.74; $p<0.01)$. A recent position statement from the Pediatric Endocrine Society notes that the diabetes diagnostic criteria are based on long-term health outcomes assessed in adults, but have not been validated in pediatric populations. ${ }^{52}$

Indices of insulin resistance. Accurate testing of IR is labor intensive, invasive, and expensive (i.e., the hyperinsulinemic-euglycemic and hyperglycemic clamp techniques). ${ }^{53}$ Therefore, several indices have been developed and studied, such as the homeostatic model assessment of insulin resistance (HOMA-IR), the quantitative insulin sensitivity check index, the continuous infusion of glucose with model assessment, and the Matsuda index. ${ }^{54-60}$ The most widely used and studied is HOMA-IR. No known international standards for abnormal levels currently exist for these indices in children, the assay itself is not standardized, and studies have shown that insulin indices do not substantially change predictive value for diabetes beyond other more-routine measures. ${ }^{29,61}$ The findings of these studies highlight the concern that insulin levels may

\section{Table 2. Comparison of Tests To Screen for Prediabetes

\begin{tabular}{|c|c|}
\hline Fasting plasma glucose & Hemoglobin Alc \\
\hline $\begin{array}{l}\text { - Higher sensitivity compared } \\
\text { to AIc in adult populations } \\
\text { (in adults up to one third } \\
\text { more diagnosed) }{ }^{50} \\
\text { - Unaffected by conditions } \\
\text { associated with high red blood } \\
\text { cell turnover (e.g., anemia, } \\
\text { blood transfusion, pregnancy) } \\
\text { - Less expensive and more } \\
\text { convenient compared to OGTT } \\
\text { - Low reproducibility }\end{array}$ & $\begin{array}{l}\text { - Fasting is not required. } \\
\text { - Low intraindividual variability } \\
\text { - Less day-to-day variability with } \\
\text { illness or stress } \\
\text { - Reflects glycemic levels for the } \\
\text { past } 3 \text { months } \\
\text { - Good predictor of diabetes- } \\
\text { related complications } \\
\text { in adults }\end{array}$ \\
\hline
\end{tabular}

OGTT, oral glucose tolerance test; Alc, glycosylated hemoglobin.

\begin{tabular}{|c|c|c|}
\hline & Prediabetes & Diabetes $^{d}$ \\
\hline Fasting plasma glucose ${ }^{a}$ & $100-125 \mathrm{mg} / \mathrm{dL}$ & $\geq 126 \mathrm{mg} / \mathrm{dL}$ \\
\hline 2-hour plasma glucose $(\mathrm{OGTT})^{\mathrm{b}}$ & $140-199 \mathrm{mg} / \mathrm{dL}$ & $\geq 200 \mathrm{mg} / \mathrm{dL}$ \\
\hline Random plasma glucose ${ }^{c}$ & Not applicable & $\geq 200 \mathrm{mg} / \mathrm{dL}$ \\
\hline Hemoglobin Alc & $5.7-6.4 \%$ & $\geq 6.5 \%$ \\
\hline
\end{tabular}

Adapted from the American Diabetes Association Recommendations. ${ }^{50}$

${ }^{\text {a }}$ Fasting for at least 8 hours with no calorie intake.

bOGTT using a load $1.75 \mathrm{~g} / \mathrm{kg}$ of body weight of glucose with a maximum of $75 \mathrm{~g}$.

In patients with hyperglycemic crises or classic symptoms of hyperglycemia (e.g., polyuria, polydipsia).

In the absence of unequivocal hyperglycemia, diagnosis is confirmed if two different tests are above threshold or a single test is above threshold twice.

OGTT, oral glucose tolerance test; Alc, glycosylated hemoglobin.

be a poor predictor of diabetes risk because, whereas IR may be accompanied by high insulin levels initially, insulin secretion may decrease later in the progression toward diabetes as a result of glucotoxicity and beta-cell failure.

Clinical practice findings for tests used to screen for prediabetes. All 28 respondents reported screening for prediabetes, using a variety of test combinations. The most widely used tests were A1c $(n=23)$ and FPG $(n=22)$, with OGTT used less often $(n=10)$. Three clinics used A1c alone, five used fasting glucose alone, 14 used fasting glucose plus A1c, and six used all three tests for initial screening. Most respondents repeated normal laboratory tests either in 12 months $(n=9)$ or between 6 and 12 months $(n=9)$. Some respondents repeated normal labs sooner, at 3-6 months $(n=5)$ and later at 12-24 months $(n=2)$. For abnormal laboratory tests, most repeated tests at either 3-6 $(n=9)$ or 6-12 months $(n=8)$. A few $(n=3)$ repeated screening on an as-needed basis.

Clinical practice findings for screening for insulin resistance. All respondents reported screening for IR by assessing for acanthosis nigricans on physical examination. Twenty-two of 25 (88\%) respondents screened for IR using fasting insulin or a ratio of fasting glucose to insulin. There was marked variability in the criteria used to identify children to be screened: Thirteen clinics $(52 \%)$ screened all children who were referred for weight management. Of the remaining 12 clinics, four used BMI percentile criteria only (two >95th and two >99th), six used the presence of acanthosis nigricans and a BMI cutoff (one $>85$ th percentile with risk factors and five $>95$ th percentile), and 
two used a cutoff based on onset of puberty and BMI $>85$ th percentile. Additional screening factors used included family history of T2DM $(n=3)$ and ethnicity $(n=1)$. Three clinics choosing not to screen for insulin levels reported the following reasons: Data did not change management, desire to conserve financial resources, and advice from endocrinologists at the institution who recommended screening for abnormal blood glucose measures only.

Consensus statement of Focus on a Fitter Future on clinical screening using laboratory tests. FPG, A1c, and OGTT can be used to screen for prediabetes in children presenting to tertiary weight management programs at the earlier age of 10 or onset of puberty (Evidence B; see Table 1 for details). The authors recognize the option for clinicians to select from one or more of the available tests.

Testing can be considered in younger children with severe obesity or children prescribed SGAPs.

The authors do not support laboratory screening for fasting insulin in obese patients because current evidence does not indicate changes to treatment based on results, and insulin levels may be low as patients lose insulin secretory ability. Thus, low insulin levels may represent worsening of beta-cell status, rather than improvement in IR (Evidence D).

Further study is needed of the predictive value of laboratory markers of blood glucose and IR over time for progression to T2DM, especially in severely obese children and other groups expected to be at highest risk.

\section{Type 2 Diabetes Prevention}

Halting the progression toward T2DM, both from normal glucose regulation to prediabetes and from prediabetes to diabetes, is one of the key goals of obesity management. Several studies have shown that lifestyle change consisting of physical activity, lower daily energy intake, and modest weight reduction can reduce T2DM incidence in adults at high risk for diabetes. ${ }^{31,62-64}$ The progression to T2DM typically occurs in individuals who are overweight or obese and sedentary. Resistance to the action of insulin in liver and skeletal muscle can lead to hyperinsulinemia, often marked by the presence of acanthosis nigricans, especially in more darkly pigmented individuals. Pancreatic beta cells may eventually fatigue as IR worsens, and waning insulin secretion leads to moderate glucose excursions in prediabetes. More-advanced beta-cell failure, in the presence of persistent IR, results in overt T2DM as glucose toxicity further impairs insulin secretion and leads blood glucose to rise uncontrollably. ${ }^{65}$ Intensifying interventions early in the disease course, with the goals of glucose normalization and preservation of pancreatic betacell function, seems to offer the best chance for preventing the development of diabetes or slowing the progression to diabetes. ${ }^{31}$ While new cases of T2DM occurred in the intervention arms of the DPP over time, the incidence of T2DM remained below that of the control group. Thus, the ADA's Professional Practice Committee recommends that adults with prediabetes be referred to a program targeting weight loss of $7 \%$ and increasing moderate physical activity to $>150$ minutes per week based on data from the DPP. ${ }^{50}$ Studies in adolescents have also demonstrated an increase in insulin sensitivity with diet and exercise-induced weight $\operatorname{loss}^{66,67}$ and resolution of prediabetes in multicomponent lifestyle programs. ${ }^{68-70}$

Role of medication in diabetes prevention. IR precedes development of T2DM, which occurs when pancreatic beta cells fail to compensate for IR. Several large RCTs of pharmacological interventions to decrease the incidence of new-onset T2DM have been conducted in adults with mixed results. ${ }^{71,72}$ Metformin, a biguanide, decreases hepatic glucose production and also increases insulin sensitivity in peripheral tissues. ${ }^{73}$ In the DPP trial, metformin, at a dose of $850 \mathrm{mg}$ twice-daily, showed a $31 \%$ reduction in risk, compared to placebo, over 2.8 years (compared to a $58 \%$ reduction in the lifestyle group). ${ }^{31,50} \mathrm{~A}$ meta-analysis from five randomized clinical trials of adults on metformin found a $40 \%$ decline in progression to type 2 diabetes among those at risk. ${ }^{72}$

In obese adolescents, a meta-analysis including three small, short-term randomized trials of metformin with IR found a reduction in BMI and fasting insulin with treatment. ${ }^{74}$ Three other small randomized trials in normoglycemic obese children with elevated fasting insulin showed reduction in fasting glucose and insulin. ${ }^{75-77}$ However, none of these studies lasted longer than 6 months.

Clinical practice findings for use of metformin in prediabetes. Among children's hospital obesity programs, 14 of 28 respondents $(50 \%)$ indicated that they use metformin to treat prediabetes, and the doses prescribed ranged from 500 to $2000 \mathrm{mg}$ per day. Seven of these 14 clinics treating prediabetes with metformin reported systematically tracking patient results, including BMI and laboratory values. Eight respondents reported using laboratory triggers for referral to endocrinology: elevated fasting glucose $>100 \mathrm{mg} / \mathrm{dL}(n=4)$, abnormal OGTT $(n=3)$, and A1c $>5.7 \%(n=1)$. Reasons for stopping metformin included improvement in blood glucose $(n=5)$, decrease in BMI of $2 \mathrm{~kg} / \mathrm{m}^{2}(n=1)$, and improvement in insulin $(n=1)$. Three respondents indicated that an endocrinologist was routinely consulted regarding the decision to stop metformin.

Clinical practice findings for use of metformin in insulin resistance. In addition to the use of metformin for prediabetes, 11 programs reported prescribing metformin for elevated fasting insulin or HOMA-IR in the absence of abnormal blood sugar or polycystic ovary syndrome. 
Consensus statement of Focus on a Fitter Future on type 2 diabetes mellitus prevention using pharmaceuticals. The Committee takes no position on the use of pharmacological agents to prevent T2DM in children with prediabetes or elevated fasting insulin, given the limited studies in children and evidence that many children with prediabetes may revert to normoglycemia without pharmacological treatment (Evidence C). The authors call for further long-term study of the safety and efficacy of medication treatment of prediabetes to prevent T2DM in children, recognizing that the scale of such a study must be large and the duration long, even when populations at highest risk of T2DM are targeted.

Role of nutrition in diabetes prevention. Support for healthy nutrition is essential for management and prevention of diabetes. Medical nutrition therapy with a registered dietitian provides specialized support in treating youth with prediabetes and T2DM. Of note, studies of dietary interventions reviewed below have employed registered dietitians to design and deliver the nutrition interventions. Weight loss of $5-7 \%$ is the standard recommendation for diabetes prevention in adults based on the DPP, which used a low-fat diet to decrease calorie intake. ${ }^{78}$ Research studies to inform similar recommendations in youth are needed, especially during critical periods of increased IR, such as puberty. ${ }^{79}$ Studies suggest that lifestyle intervention in children also leads to metabolic improvement. ${ }^{80}$

Although there is no prescribed diet for diabetes prevention in youth, research on low glycemic diets among adults $^{81-83}$ and youth ${ }^{84-88}$ demonstrate improvement in insulin secretion and body composition without evidence of harm. A low glycemic index (GI) diet generally refers to a balanced diet with carbohydrate content primarily from low to medium glycemic load foods (those that produce less-rapid rise in blood glucose and have lower overall carbohydrate content). ${ }^{89}$ The most common high GI foods include processed grains (white bread and white rice) and added sugars of all types. In two studies comparing low and high GI diets in 38 youth with obesity and T2DM or prediabetes, the low GI diet had significantly greater reductions in IR. ${ }^{86,87}$ Additional research found a low GI diet decreased adipose tissue more than low-kilocalorie and low-fat diets ${ }^{67,88}$ and increased high-density lipoprotein cholesterol and satiety. ${ }^{88}$ An RCT comparing low versus high glycemic load hypocaloric diets for 6 months found greater reductions in waist circumference, BMI $z$-score, and HOMA-IR with the low GI diet. ${ }^{90}$

In children who are severely obese, few studies examined the safety and effectiveness of rapid weight loss diets. A study of 46 adolescents randomized to a low-calorie, low-fat diet or a very-low-carbohydrate ( $20 \mathrm{~g}$ /day) diet demonstrated safety and efficacy of the very-low-carbohydrate diet. ${ }^{91}$ Another study comparing 58 children randomized to either a very-low-carbohydrate ketogenic diet or a hypocaloric diet for 6 months found greater improvements with the ketogenic diet in weight, fat mass, waist circumference, fasting insulin, and HOMA-IR. ${ }^{92}$ Larger and longer-term studies of verylow-carbohydrate diets for severely obese children with prediabetes are needed.

Role of exercise in diabetes prevention. Exercise, combined with healthful dietary changes using a behavioral approach, is a key therapeutic recommendation for obesity reduction and T2DM prevention. ${ }^{32}$ In studies of adults, exercise increases insulin sensitivity within 1 week of an intervention, lasting for 3-4 days after exercising. ${ }^{93}$ In obese children, exercise alone has been shown to improve IR even without changes in body weight or body composition. A variety of exercise interventions have been tested, including 1-hour circuit training sessions three times per week, sports activities for 20-45 minutes three times per week, and progressive resistance training. ${ }^{94-96}$ Individual differences in physiological changes with exercise depend on baseline fitness, genetic effects, and lifestyle. ${ }^{97}$

Consensus statements of Focus on a Fitter Future on T2DM prevention using diet and physical activity. The Committee supports dietary intervention to manage weight, specifically a low GI diet implemented by registered dietitians, to influence metabolic risk factors for T2DM in prediabetic children (Level of Evidence B). More-severe carbohydrate restriction may be considered for severely obese children with prediabetes under medical supervision. More study is needed on long-term effects of diet on T2DM prevention in severely obese children and adolescents. For physical activity, though there are no pediatric recommendations for exercise specifically to prevent diabetes, the Committee strongly supports an increased level of moderate-to-vigorous physical activity for children with prediabetes (Evidence B). The AAP recommends 60 minutes of moderate-to-vigorous activity daily for all youth. ${ }^{32}$

Role of behavioral health professionals in diabetes prevention. Standard practice for treating childhood obesity in multidisciplinary referral settings includes behavioral health services ${ }^{32}$ delivered by a doctoral-level pediatric psychologist, if possible. There is emerging literature underscoring the benefits of including a behavioral health specialist in treating T2DM. ${ }^{98,99}$ Earlier involvement of behavioral health professionals for those with prediabetes may help prevent disease progression. As in treating obesity, ${ }^{32,100}$ targeting behavioral treatment to the family unit of youth with prediabetes or T2DM may be especially important, given high rates of T2DM and problematic behaviors among family members.

In addition to facilitating family-based lifestyle behavior change, psychologists can address comorbid psychopathology that contributes to disease progression or hinders treatment. Emotional and behavioral difficulties represent barriers to adherence with pediatric medical regimens in 
general. ${ }^{101}$ Almost 1 in 5 youth with newly diagnosed T2DM may have pre-existing psychiatric diagnoses. ${ }^{102}$ Researchers have found that the progression of IR during childhood and adolescence is predicted by depressive symptomatology at baseline, independent of BMI. ${ }^{103}$ Psychologists also can be instrumental in addressing other adherence barriers, such as family conflict and poor time management. ${ }^{101}$

Psychologists can aid a multidisciplinary team in providing culturally effective pediatric healthcare. ${ }^{104}$ Children and adolescents from low socioeconomic backgrounds, ethnic minority groups, and single-parent families tend to have more problems with adherence to complex chronic disease regimens. ${ }^{101}$ In general, racial and ethnic minorities utilize mental health services at lower rates than non-Latino whites. ${ }^{105,106}$ Therefore, pediatric psychologists working with children and adolescents with prediabetes should be sensitive to cultural issues and tailor their interventions for each family. ${ }^{107}$

Consensus statement of Focus on a Fitter Future on the role of behavioral health professionals in T2DM prevention. The Committee supports including pediatric psychologists, or other trained behavioral health specialists, in care teams to manage prediabetes using behavioral treatment approaches (Evidence C).

\section{Referral to Endocrinology/Diabetes Specialists}

The ADA recommendations state that children meeting criteria for T2DM are to be referred to endocrine specialists to confirm diagnosis and discuss decisions about medication and how to manage comorbidities. ${ }^{50}$ An endocrinologist should be consulted to distinguish between type 1 and 2 diabetes. ${ }^{2}$ The AAP recommends that weight management specialists co-manage T2DM with a pediatric endocrinologist. ${ }^{108}$ A primary care professional (pediatrician, family practitioner, or internist) who has expertise in diabetes management may serve as a consultant in the absence of an available pediatric endocrinologist. ${ }^{50}$

Clinical practice findings for co-management with an endocrinologist. Whereas some pediatric obesity clinics are directed by an endocrinologist, others have more-limited access to endocrinologists. Almost all of the children's hospital obesity clinics in our survey $(n=23$ of $25 ; 92 \%)$ do not include endocrinologists on the weight management team; all of these refer patients with T2DM to endocrinology, primarily for medication management. The majority of respondents $(n=16$ of $22 ; 72 \%)$ indicated that they do not refer patients with prediabetes to endocrinologists.

Consensus statement of Focus on a Fitter Future on co-management of T2DM with an endocrinologist. Consistent with AAP recommendations ${ }^{108}$ the Committee supports that weight management specialists co-manage T2DM with a pediatric endocrinologist (Evidence D).

\section{Conclusion}

Given the increased prevalence of prediabetes and T2DM among children, guidance regarding screening and management of prediabetes is needed to ensure best clinical outcomes and reduce healthcare costs. However, data to guide T2DM prevention in children are limited. This article summarizes the current literature on screening and diagnosis of prediabetes and the prevention of T2DM among overweight youth. Variability in practices in assessment and treatment of IR and prediabetes may be attributed to the lack of high-quality evidence and limited availability of pediatric endocrinology expertise. Based on the best available evidence, our experience in treating obese children, and consideration of possible harms and benefits, the authors offer statements of support reflecting consensus of the FFF Medical Management Committee with consideration of the level of evidence, uniformity of current practice, potential costs, and benefits for practices that were reviewed (Table 4).

Further research is needed to guide which therapies might best prevent progression of prediabetes to T2DM and which children should be targeted. In order to answer important clinical and public health questions, large-scale, multi-center studies of interventions to reduce the risk of T2DM are needed. A multi-center research network of childhood obesity treatment programs, working collaboratively with multidisciplinary teams including pediatric endocrinologists, could provide the platform required to answer many of these questions.

\section{Acknowledgments}

Between 2008 and 2013, CHA (formerly known as NACHRI, the National Association of Children's Hospitals and Related Institutions) convened FFF to articulate the role of children's hospitals in combating pediatric obesity while building consensus on performance measurement and quality improvement. FFF examined the state of care for obese children and adolescents and continues to communicate the best ways to ensure their physical well-being and emotional safety. FFF was guided by multidisciplinary teams representing more than a dozen pediatric healthcare professions - physicians of several specialties, dietitians, exercise specialists, nurses, physical therapists, obesity program managers, psychologists, and social workers - involved with childhood obesity. This article represents the work of the Medical Treatment Committee in consensus with the entire FFF group. FFF was funded, in part, by the Mattel Children's Foundation. Dr. Haemer was supported by the Children's Hospital Colorado Research Institute Research Scholar Award. Dr. Rhodes was supported by the New Balance Foundation Obesity Prevention Center Boston Children's Hospital.

\section{Author Disclosure Statement}

CHA (the Association) was the project sponsor. The sponsor facilitated collection of data and hosted study 


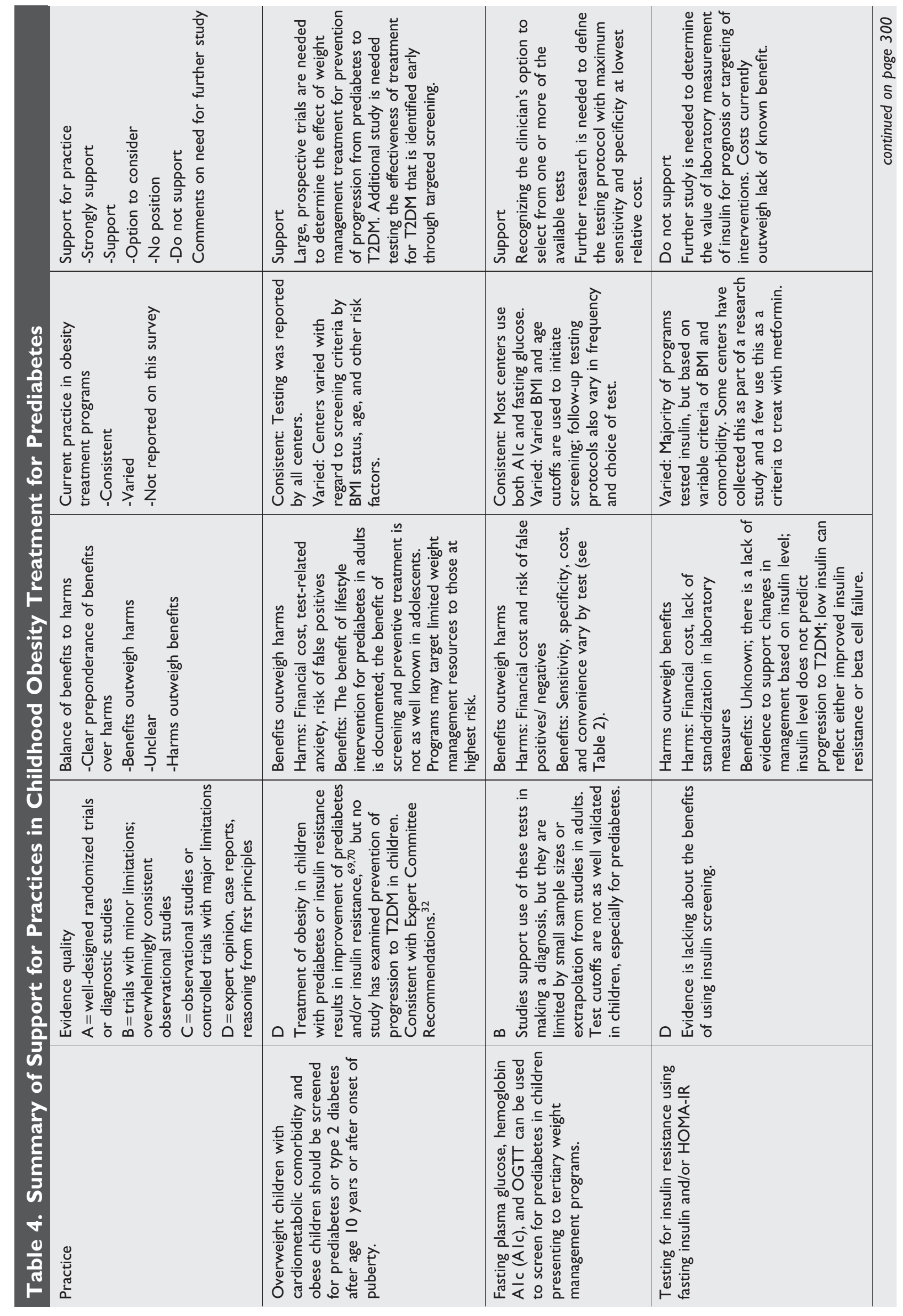




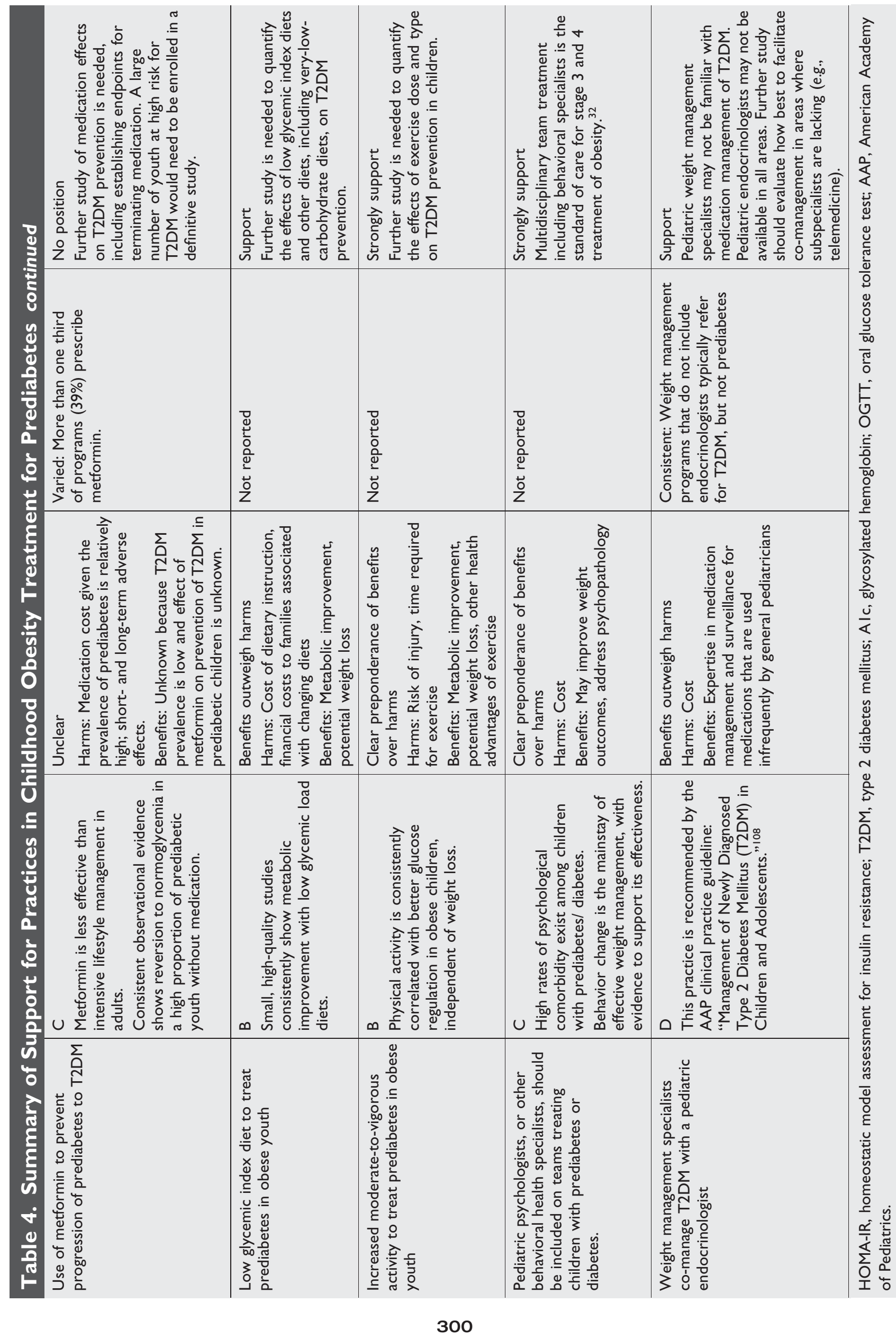


group meetings, but was not involved in the data analysis or the decision to submit the manuscript for publication. The views expressed are those of the authors and do not necessarily reflect those of the Association. Dr. Rhodes reports receiving research funding from Merck, and her spouse owns stock in Bristol-Myers Squibb. The remaining authors have no disclosures.

\section{References}

1. May AL, Kuklina EV, Yoon PW. Prevalence of cardiovascular disease risk factors among US adolescents, 1999-2008. Pediatrics 2012;129:1035-1041.

2. Gahagan S, Silverstein J. Prevention and treatment of type 2 diabetes mellitus in children, with special emphasis on American Indian and Alaska Native children. American Academy of Pediatrics Committee on Native American Child Health. Pediatrics 2003;112:e328

3. Jones KL. Role of obesity in complicating and confusing the diagnosis and treatment of diabetes in children. Pediatrics 2008; 121:361-368

4. Dabelea D, Pihoker C, Talton JW, et al. Etiological approach to characterization of diabetes type: The SEARCH for Diabetes in Youth Study. Diabetes Care 2011;34:1628-1633.

5. Inzucchi SE. Clinical practice. Diagnosis of diabetes. $N$ Engl $J$ Med 2012;367:542-550.

6. Boyle JP, Thompson TJ, Gregg EW, et al. Projection of the year 2050 burden of diabetes in the US adult population: Dynamic modeling of incidence, mortality, and prediabetes prevalence. Popul Health Metr 2010;8:29.

7. Rhodes ET, Prosser LA, Hoerger TJ, et al. Estimated morbidity and mortality in adolescents and young adults diagnosed with type 2 diabetes mellitus. Diabet Med 2012;29:453-463.

8. Johnson ST, Newton AS, Chopra M, et al. In search of quality evidence for lifestyle management and glycemic control in children and adolescents with type 2 diabetes: A systematic review. BMC Pediatr 2010;10:97.

9. Rothman RL, Mulvaney S, Elasy TA, et al. Self-management behaviors, racial disparities, and glycemic control among adolescents with type 2 diabetes. Pediatrics 2008;121:e912-e919.

10. Dabelea D, Bell RA, D'Agostino RB, Jr., et al. Writing Group for the SEARCH for Diabetes in Youth Study Group. Incidence of diabetes in youth in the United States. JAMA 2007;297:2716-2724.

11. Cavanaugh K, Huizinga MM, Wallston KA, et al. Association of numeracy and diabetes control. Ann Intern Med 2008;148:737-746.

12. Bacha F, Pyle L, Nadeau K, et al. Determinants of glycemic control in youth with type 2 diabetes at randomization in the TODAY study. Pediatr Diabetes 2012;13:376-383.

13. Bacha F, Gungor N, Lee S, et al. Progressive deterioration of beta-cell function in obese youth with type 2 diabetes. Pediatr Diabetes 2013;14:106-111.

14. Giannini C, Weiss R, Cali A, et al. Evidence for early defects in insulin sensitivity and secretion before the onset of glucose dysregulation in obese youths: A longitudinal study. Diabetes 2012;61:606-614.

15. Zeitler P, Hirst K, Pyle L, et al.; TODAY Study Group. A clinical trial to maintain glycemic control in youth with type 2 diabetes. N Engl J Med 2012;366:2247-2256.

16. Mayer-Davis EJ, Bell RA, Dabelea D, et al. The many faces of diabetes in American youth: Type 1 and type 2 diabetes in five race and ethnic populations. The SEARCH for Diabetes in Youth Study. Diabetes Care 2009;32(Suppl 2):S99-S101.

17. Bell RA, Mayer-Davis EJ, Beyer JW, et al. Diabetes in nonHispanic white youth: Prevalence, incidence, and clinical characteristics. The SEARCH for Diabetes in Youth Study. Diabetes Care 2009;32(Suppl 2):S102-S111.

18. Mayer-Davis EJ, Beyer J, Bell RA, et al. Diabetes in African American youth: Prevalence, incidence, and clinical characteristics: The SEARCH for Diabetes in Youth Study. Diabetes Care 2009;32(Suppl 2):S112-S122.

19. Lawrence JM, Mayer-Davis EJ, Reynolds K, et al. Diabetes in Hispanic American youth: Prevalence, incidence, demographics, and clinical characteristics. The SEARCH for Diabetes in Youth Study. Diabetes Care 2009;32(Suppl 2):S123-S132.

20. Liu LL, Yi JP, Beyer J, et al. Type 1 and type 2 diabetes in Asian and Pacific Islander US youth. The SEARCH for Diabetes in Youth Study. Diabetes Care 2009;32(Suppl 2):S133-S140.

21. Dabelea D, DeGroat J, Sorrelman C, et al. Diabetes in Navajo youth: Prevalence, incidence, and clinical characteristics. The SEARCH for Diabetes in Youth Study. Diabetes Care 2009; 32(Suppl 2):S141-S147.

22. Goran MI, Ball GD, Cruz ML. Obesity and risk of type 2 diabetes and cardiovascular disease in children and adolescents. $J$ Clin Endocrinol Metab 2003;88:1417-1427.

23. Huang TT, Goran MI. Prevention of type 2 diabetes in young people: A theoretical perspective. Pediatr Diabetes 2003;4: $38-56$.

24. Liu L, Hironaka K, Pihoker C. Type 2 diabetes in youth. Curr Probl Pediatr Adolesc Health Care 2004;34:254-272.

25. Liese AD, D'Agostino RB, Jr., Hamman RF, et al. The burden of diabetes mellitus among US youth: Prevalence estimates from the SEARCH for Diabetes in Youth Study. Pediatrics 2006;118: $1510-1518$.

26. Focus on a Fitter Future National Workgroups on Childhood Obesity, 2008-2013. Available at www.childrenshospitals.net/ AM/Template.cfm?Section $=$ Obesity $5 \&$ template $=/ \mathrm{CM} /$ Content Display.cfm\&ContentID = 70361 Last accessed April 28, 2014 .

27. American Academy of Pediatrics Steering Committee on Quality Improvement and Management. Classifying recommendations for clinical practice guidelines. Pediatrics 2004;114:874-877.

28. [No Authors Listed]. Report of the Expert Committee on the Diagnosis and Classification of Diabetes Mellitus. Diabetes Care 1997;20:1183-1197.

29. Weiss R, Taksali SE, Tamborlane WV, et al. Predictors of changes in glucose tolerance status in obese youth. Diabetes Care 2005;28:902-909.

30. Kleber M, deSousa G, Papcke S, et al. Impaired glucose tolerance in obese white children and adolescents: Three to five year follow-up in untreated patients. Exp Clin Endocrinol Diabetes 2011;119:172-176.

31. Knowler WC, Barrett-Connor E, Fowler SE, et al. Reduction in the incidence of type 2 diabetes with lifestyle intervention or metformin. N Engl J Med 2002;346:393-403.

32. Barlow SE. Expert committee recommendations regarding the prevention, assessment, and treatment of child and adolescent overweight and obesity: Summary report. Pediatrics 2007;120(Suppl 4): S164-S192.

33. Nathan B. The increase of type 2 diabetes mellitus in children Minn Med 2007;90:39-43.

34. Pinhas-Hamiel O, Dolan LM, Daniels SR, et al. Increased incidence of non-insulin-dependent diabetes mellitus among adolescents. J Pediatr 1996;128:608-615. 
35. Kaufman FR. Type 2 diabetes mellitus in children and youth: A new epidemic. J Pediatr Endocrinol Metab 2002;15(Suppl 2):737-744.

36. Kaufman FR. Type 2 diabetes in children and youth. Endocrinol Metab Clin North Am 2005;34:659-676.

37. Silverstein JH, Rosenbloom AL. Type 2 diabetes in children. Curr Diab Rep 2001;1:19-27.

38. [No Authors Listed]. Type 2 diabetes in children and adolescents. American Diabetes Association. Diabetes Care 2000;23:381389.

39. Franks PW, Hanson RL, Knowler WC, et al. Childhood predictors of young-onset type 2 diabetes. Diabetes 2007;56:29642972.

40. Murtaugh MA, Jacobs DR, Jr., Moran A, et al. Relation of birth weight to fasting insulin, insulin resistance, and body size in adolescence. Diabetes Care 2003;26:187-192.

41. Hovi P, Andersson S, Eriksson JG, et al. Glucose regulation in young adults with very low birth weight. $N$ Engl J Med 2007; 356:2053-2063.

42. Boney CM, Verma A, Tucker R, et al. Metabolic syndrome in childhood: Association with birth weight, maternal obesity, and gestational diabetes mellitus. Pediatrics 2005;115:e290-e296.

43. Soto N, Bazaes RA, Pena V, et al. Insulin sensitivity and secretion are related to catch-up growth in small-for-gestational-age infants at age 1 year: Results from a prospective cohort. J Clin Endocrinol Metab 2003;88:3645-3650.

44. Sugihara S, Sasaki N, Amemiya S, et al. Analysis of weight at birth and at diagnosis of childhood-onset type 2 diabetes mellitus in Japan. Pediatr Diabetes 2008;9:285-290.

45. Kahn BB, Flier JS. Obesity and insulin resistance. J Clin Invest 2000;106:473-481.

46. Caprio S. Relationship between abdominal visceral fat and metabolic risk factors in obese adolescents. Am J Hum Biol 1999;11: 259-266.

47. American Diabetes Association, American Psychiatric Association, American Association of Clinical Endocrinologists, et al. Consensus development conference on antipsychotic drugs and obesity and diabetes. Diabetes Care 2004;27:596-601.

48. Andrade SE, Lo JC, Roblin D, et al. Antipsychotic medication use among children and risk of diabetes mellitus. Pediatrics 2011;128:1135-1141.

49. Correll CU, Manu P, Olshanskiy V, et al. Cardiometabolic risk of second-generation antipsychotic medications during first-time use in children and adolescents. JAMA 2009;302:1765-1773.

50. American Diabetes Association. Diagnosis and classification of diabetes mellitus. Diabetes Care 2012;35(Suppl 1):S64-S71.

51. Lee JM, Gebremariam A, Woolford SJ, et al. A risk score for identifying overweight adolescents with dysglycemia in primary care settings. J Pediatr Endocrinol Metab 2013;26:477-488.

52. Kapadia C, Zeitler P; Drugs and Therapeutics Committee of the Pediatric Endocrine Society. Hemoglobin A1c measurement for the diagnosis of type 2 diabetes in children. Int J Pediatr Endocrinol 2012;2012:31.

53. DeFronzo RA, Tobin JD, Andres R. Glucose clamp technique: A method for quantifying insulin secretion and resistance. $A m J$ Physiol 1979;237:E214-E223.

54. Matthews DR, Hosker JP, Rudenski AS, et al. Homeostasis model assessment: Insulin resistance and beta-cell function from fasting plasma glucose and insulin concentrations in man. Diabetologia 1985;28:412-419.

55. Hosker JP, Matthews DR, Rudenski AS, et al. Continuous infusion of glucose with model assessment: Measurement of insulin resistance and beta-cell function in man. Diabetologia 1985;28: 401-411.

56. Katz A, Nambi SS, Mather K, et al. Quantitative insulin sensitivity check index: A simple, accurate method for assessing insulin sensitivity in humans. $J$ Clin Endocrinol Metab 2000;85: $2402-2410$.

57. Hermans MP, Levy JC, Morris RJ, et al. Comparison of insulin sensitivity tests across a range of glucose tolerance from normal to diabetes. Diabetologia 1999;42:678-687.

58. Muniyappa R, Lee S, Chen H, et al. Current approaches for assessing insulin sensitivity and resistance in vivo: Advantages, limitations, and appropriate usage. Am J Physiol Endocrinol Metab 2008;294:E15-E26.

59. Hrebicek J, Janout V, Malincikova J, et al. Detection of insulin resistance by simple quantitative insulin sensitivity check index QUICKI for epidemiological assessment and prevention. $J$ Clin Endocrinol Metab 2002;87:144-147.

60. Kanauchi M. A new index of insulin sensitivity obtained from the oral glucose tolerance test applicable to advanced type 2 diabetes. Diabetes Care 2002;25:1891-1892.

61. Wilson PW, Meigs JB, Sullivan L, et al. Prediction of incident diabetes mellitus in middle-aged adults: The Framingham Offspring Study. Arch Intern Med 2007;167:1068-1074.

62. Pan XR, Li GW, Hu YH, et al. Effects of diet and exercise in preventing NIDDM in people with impaired glucose tolerance. The Da Qing IGT and Diabetes Study. Diabetes Care 1997;20: 537-544.

63. Tuomilehto J, Lindstrom J, Eriksson JG, et al. Prevention of type 2 diabetes mellitus by changes in lifestyle among subjects with impaired glucose tolerance. N Engl J Med 2001;344:1343-1350.

64. Perreault L, Pan Q, Mather KJ, et al. Effect of regression from prediabetes to normal glucose regulation on long-term reduction in diabetes risk: Results from the Diabetes Prevention Program Outcomes Study. Lancet 2012;379:2243-2251.

65. Samson SL, Garber AJ. Metabolic syndrome. Endocrinol Metab Clin North Am 2014;43:1-23.

66. Steffen LM, Jacobs DR, Jr., Murtaugh MA, et al. Whole grain intake is associated with lower body mass and greater insulin sensitivity among adolescents. Am J Epidemiol 2003;158:243-250.

67. Ebbeling CB, Leidig MM, Sinclair KB, et al. A reduced-glycemic load diet in the treatment of adolescent obesity. Arch Pediatr Adolesc Med 2003;157:773-779.

68. Shaw M, Savoye M, Cali A, et al. Effect of a successful intensive lifestyle program on insulin sensitivity and glucose tolerance in obese youth. Diabetes Care 2009;32:45-47.

69. Savoye M, Shaw M, Dziura J, et al. Effects of a weight management program on body composition and metabolic parameters in overweight children: A randomized controlled trial. JAMA 2007;297:2697-2704

70. Savoye M, Caprio S, Dziura J, et al. Reversal of early abnormalities in glucose metabolism in obese youth: Results of an intensive lifestyle randomized controlled trial. Diabetes Care 2014;37:317-324.

71. DeFronzo RA, Abdul-Ghani M. Type 2 diabetes can be prevented with early pharmacological intervention. Diabetes Care 2011; 34(Suppl 2):S202-S209.

72. Salpeter SR, Buckley NS, Kahn JA, et al. Meta-analysis: Metformin treatment in persons at risk for diabetes mellitus. $\mathrm{Am} J$ Med 2008;121:149-157.

73. Vaidyanathan J, Choe S, Sahajwalla CG. Type 2 diabetes in pediatrics and adults: Thoughts from a clinical pharmacology perspective. J Pharm Sci 2012;101:1659-1671. 
74. Quinn SM, Baur LA, Garnett SP, et al. Treatment of clinical insulin resistance in children: A systematic review. Obes Rev 2010;11:722-730.

75. Freemark M, Bursey D. The effects of metformin on body mass index and glucose tolerance in obese adolescents with fasting hyperinsulinemia and a family history of type 2 diabetes. Pediatrics 2001;107:E55.

76. Kay JP, Alemzadeh R, Langley G, et al. Beneficial effects of metformin in normoglycemic morbidly obese adolescents. Metabolism 2001;50:1457-1461.

77. Yanovski JA, Krakoff J, Salaita CG, et al. Effects of metformin on body weight and body composition in obese insulin-resistant children: A randomized clinical trial. Diabetes 2011;60:477-485.

78. Perreault L, Kahn SE, Christophi CA, et al. Regression from prediabetes to normal glucose regulation in the diabetes prevention program. Diabetes Care 2009;32:1583-1588.

79. Yajnik CS. Nutrition, growth, and body size in relation to insulin resistance and type 2 diabetes. Curr Diab Rep 2003;3:108-114.

80. Freitas Junior IF, Christofaro DG, Codogno JS, et al.The association between skipping breakfast and biochemical variables in sedentary obese children and adolescents. J Pediatr 2012;161: 871-874.

81. Esposito K, Maiorino MI, Ceriello A, et al. Prevention and control of type 2 diabetes by Mediterranean diet: A systematic review. Diabetes Res Clin Pract 2010;89:97-102.

82. Hu FB, Malik VS. Sugar-sweetened beverages and risk of obesity and type 2 diabetes: Epidemiologic evidence. Physiol Behav 2010;100:47-54.

83. Thomas T, Pfeiffer AF. Foods for the prevention of diabetes: How do they work? Diabetes Metab Res Rev 2012;28:25-49.

84. Kong AP, Chan RS, Nelson EA, et al. Role of low-glycemic index diet in management of childhood obesity. Obes Rev 2011; 12:492-498.

85. Davis JN, Ventura EE, Shaibi GQ, et al. Reduction in added sugar intake and improvement in insulin secretion in overweight Latina adolescents. Metab Syndr Relat Disord 2007;5:183-193.

86. Gellar L, Nansel TR. High and low glycemic index mixed meals and blood glucose in youth with type 2 diabetes or impaired glucose tolerance. J Pediatr 2009;154:455-458.

87. Iannuzzi A, Licenziati MR, Vacca M, et al. Comparison of two diets of varying glycemic index on carotid subclinical atherosclerosis in obese children. Heart Vessels 2009;24:419-424.

88. Fajcsak Z, Gabor A, Kovacs V, et al. The effects of 6-week low glycemic load diet based on low glycemic index foods in overweight/obese children: Pilot study. J Am Coll Nutr 2008;27:12-21.

89. Brand-Miller J, McMillan-Price J, Steinbeck K, et al. Dietary glycemic index: Health implications. J Am Coll Nutr 2009; 28(Suppl):446S-449S

90. Parillo M, Licenziati MR, Vacca M, et al. Metabolic changes after a hypocaloric, low-glycemic-index diet in obese children. $J$ Endocrinol Invest 2012;35:629-633.

91. Krebs NF, Gao D, Gralla J, et al. Efficacy and safety of a high protein, low carbohydrate diet for weight loss in severely obese adolescents. J Pediatr 2010;157:252-258.

92. Partsalaki I, Karvela A, Spiliotis BE. Metabolic impact of a ketogenic diet compared to a hypocaloric diet in obese children and adolescents. J Pediatr Endocrinol Metab 2012;25:697-704.

93. Ryan DH; Diabetes Prevention Program Research Group. Diet and exercise in the prevention of diabetes. Int J Clin Pract Suppl $2003 ; 134: 28-35$.
94. Bell LM, Watts K, Siafarikas A, et al. Exercise alone reduces insulin resistance in obese children independently of changes in body composition. J Clin Endocrinol Metab 2007;92:4230 4235.

95. Kahle EB, Zipf WB, Lamb DR, et al. Association between mild, routine exercise and improved insulin dynamics and glucose control in obese adolescents. Int J Sports Med 1996;17:1-6.

96. Shaibi GQ, Cruz ML, Ball GD, et al. Effects of resistance training on insulin sensitivity in overweight Latino adolescent males. Med Sci Sports Exerc 2006;38:1208-1215.

97. Teran-Garcia M, Rankinen T, Bouchard C. Genes, exercise, growth, and the sedentary obese child. J Appl Physiol 2008;105: 988-1001.

98. Aslander-van Vliet E, Smart C, Waldron S. Nutritional management in childhood and adolescent diabetes. Pediatr Diabetes 2007;8:323-339.

99. Rosenbloom AL, Silverstein JH, Amemiya S, et al. ISPAD Clinical Practice Consensus Guidelines 2006-2007. Type 2 diabetes mellitus in the child and adolescent. Pediatr Diabetes 2008; 9:512-526

100. Epstein LH, Wing RR, Steranchak L, et al. Comparison of family-based behavior modification and nutrition education for childhood obesity. J Pediatr Psychol 1980;5:25-36.

101. La Greca AM, Mackey ER. Adherence to pediatric treatment regimens. In: Roberts M, Steele R, eds. Handbook of Pediatric Psychology. The Guilford Press: New York, 2009.

102. Levitt Katz LE, Swami S, Abraham M, et al. Neuropsychiatric disorders at the presentation of type 2 diabetes mellitus in children. Pediatr Diabetes 2005;6:84-89.

103. Shomaker LB, Tanofsky-Kraff M, Stern EA, et al. Longitudinal study of depressive symptoms and progression of insulin resistance in youth at risk for adult obesity. Diabetes Care 2011;34: 2458-2463.

104. Spirito A, Brown RT, D'Angelo E, et al. Society of pediatric psychology task force report: Recommendations for the training of pediatric psychologists. $J$ Pediatr Psychol 2003;28: $85-98$.

105. Alegria M, Canino G, Rios R, et al. Inequalities in use of specialty mental health services among Latinos, African Americans, and Non-Latino Whites. Psychiatr Serv 2002;53:1547-1555.

106. Snowden LR, Yamada AM. Cultural differences in access to care. Annu Rev Clin Psychol 2005;1:143-166.

107. Clay DL. Cultural and diversity issues in research and practice. In: Roberts M, Steele R, eds. Handbook of Pediatric Psychology. The Guilford Press: New York, 2009.

108. Copeland KC, Silverstein J, Moore KR, et al. Management of newly diagnosed type 2 diabetes mellitus (T2DM) in children and adolescents. Pediatrics 2013;131:364-382.

Address correspondence to: Matthew A. Haemer, MD, MPH Department of Pediatrics Section of Nutrition University of Colorado School of Medicine $12631 \mathrm{E} 17^{\text {th }}$ Avenue, F561 Aurora, CO 80045

E-mail: Matthew.Haemer@ucdenver.edu 